\title{
The Saga of the HIV Controversy
}

Nobel Prize in Physiology or Medicine - 2008

Udaykumar Ranga holds a PhD in life sciences from the Jawaharlal Nehru

University, New Delhi. His laboratory at JNCASR,

Bangalore is one of the few in India that focuses on HIV pathogenesis, immune response, vaccine design and technology development. The unique nature of the laboratory is its dedication for the study of the Indian HIV-1 strains that are quite distinct and constitute the most predominant family in the world.

\section{Keywords}

HIV, AIDS, Nobel Prize in Physiology/Medicine 2008.

\section{Udaykumar Ranga}

Two scientists were honored recently with a Nobel Prize for the discovery of HIV. A third scientist was ignored. Over the past two decades, there has been a bitter controversy around the discovery of HIV. This article discusses in detail the history of the HIV discovery and the unfortunate developments that have led to the controversy.

\section{Introduction}

Beginning from 1901, the Nobel Prize has been awarded every year to men and women who made significant contributions in five different disciplines: physics, chemistry, physiology or medicine, literature and peace. The prize under the category of Physiology or Medicine for the year 2008 has been awarded for the discovery of two important viruses, the Human Papilloma Viruses (HPV) causing cervical cancer and the Human Immunodeficiency Virus (HIV) causing Acquired Immune Deficiency Syndrome or AIDS.

Harald zur Hausen of University of Düsseldorf, Germany, (Figure 1) was honored with the award for his important contributions that established the association between HPV and cervical cancer, the second most common cancer among women. He not only postulated an association between cervical cancer and HPV but also provided experimental evidence that the two variant strains of HPV, types 16 and 18, were consistently found associated with a large majority of cancers. His efforts directly influenced vaccine development and these vaccines today provide protection to more than $95 \%$ of the women who are at high risk of the viral infection. The two scientists who shared the award for discovering HIV are Françoise Barré-Sinoussi from the Pasteur Institute of France and Luc Montagnier from the World 
Foundation for AIDS Research and Prevention, Paris, France. The selection of Harald zur Hausen has been universally applauded by one and all and the same may be said for the selection of the two HIV scientists by and large. Yet a significant section of researchers complain about the omission of a third HIV scientist, Robert C Gallo from the United States of America (Figure 1). This is despite the fact that the award can be given to only three people in any year under any category.

Who is Gallo and what is all this debate about? And why all the controversy surrounding only the HIV discovery? To find answers to these questions, we must travel into the past, into the early 1980 s, to examine the unfolding of one of the worst medical calamities known as AIDS. We must consider how scientists of that era, in the absence of the sophisticated technologies that were yet to be developed, struggled to discover that unknown entity later to be known as HIV. Further, we will also witness how even reputed scientists could get carried away by a desire for fame ignoring professional ethics. We must see how they got entangled in acrimonious fights and divided the entire scientific community into rival camps for the next decade. To this asinine chaos we must also add incidences of unfortunate and inevitable laboratory contamination of the viruses that further complicated the matters. Along the way, we must learn a few basic facts on the biology of HIV without which an appreciation of the conflict is not possible.

\section{Retroviruses}

HIV belongs to a specific group of animal viruses called retroviruses. Unlike in other living organisms where the genetic information is usually stored in DNA, in retroviruses, the genetic material is RNA, not DNA (Figure 2). This genetic information first flows from RNA to DNA before resuming the natural flow again to RNA and then to protein. Since the information flow is initially reversed in this group of viruses, they are called retroviruses, retro is Latin for reverse. All retroviruses code for a special polymerase, the reverse transcriptase (RT) that can mediate the conversion of RNA into DNA and thereafter into double-

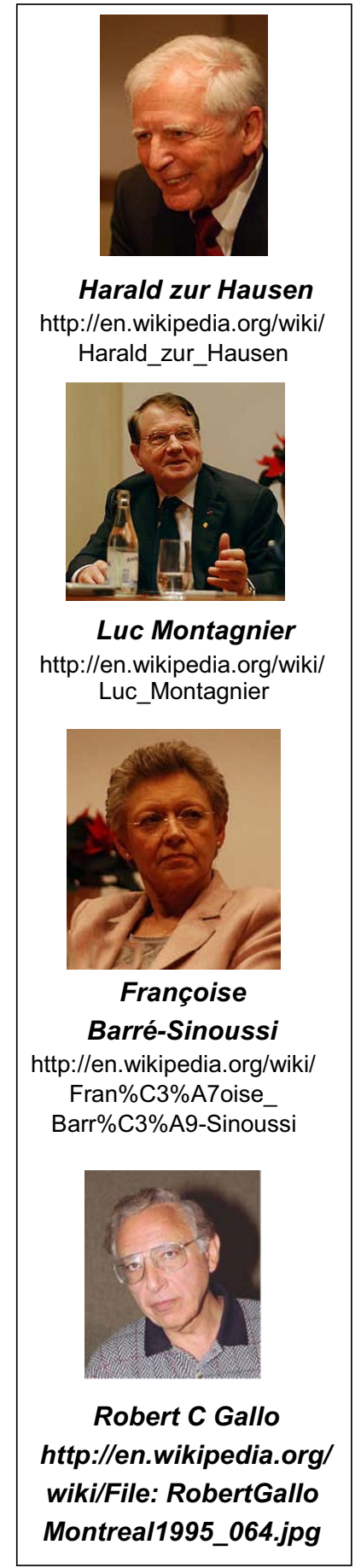

Figure 1. 


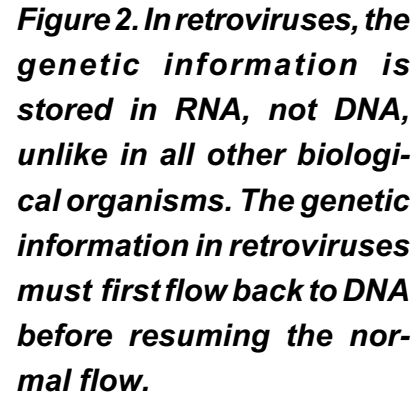

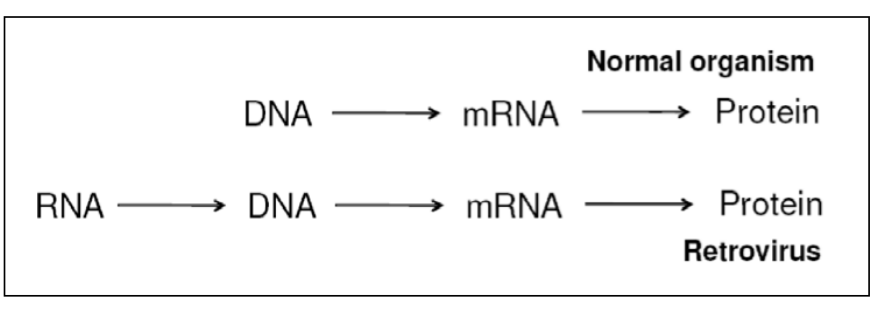

stranded DNA. Several findings over the past century contributed significantly towards the discovery of HIV. This includes the discovery of chicken tumor viruses by Peyton Rous and the finding of the reverse transcriptase enzyme independently by Howard Martin Temin and David Baltimore (see Box 1). Development of the RT assay also played an important role in the discovery of HIV-1 and other retroviruses (see Box 2).

\section{Box 1. The pre-HIV Era: A Hunt for Tumor Causing Viruses in Human Beings}

Tumor causing viruses (oncoviruses) have been described more than half a century prior to the discovery of Reverse Transcriptase. Peyton Rous discovered tumor causing viruses in chicken for which he was awarded the Nobel Prize in 1966. This finding was followed by the discovery of several other RNA and DNA viruses that cause tumors in several species including the mouse. The oncoviruses typically mediate transformation of cultured host cells in which they propagate. Transformation is a process by means of which a normal cell is converted into a cancer cell that escapes normal checks on the cell division and keeps multiplying endlessly. This can also happen by mutations in the genes responsible for such checks. One spin-off benefit of the discovery of such transformation was that it facilitated culture of cells under laboratory conditions by establishing transformed 'cell lines' from several animal and human tissues, which otherwise could not be maintained in vitro for long. Both RNA and DNA viruses were found to transform cells and cause tumors in animals. Renato Dulbecco demonstrated the presence of viral DNA in the transformed tumor cells thus providing a link between viruses and tumors for the first time. For this discovery he was awarded the Nobel Prize for the year 1975 which he shared with Temin and Baltimore. Even after Dulbecco's work, it still remained a mystery as to how RNA viruses could be associated with the DNA of the transformed cells in tumors. Temin was the first to propose that the RNA viruses somehow converted their RNA into DNA which then possibly got associated with the cellular DNA that could be inherited by the daughter cells. In other words, he predicted that retroviruses have an intermediate DNA step and this DNA was integrated into host chromosome, a prediction that turned out to be correct later. Today, we know that the RT enzyme converts viral RNA of the retroviruses into DNA that finally integrates into the host cellular DNA which could be transmitted from cell to cell as the cells divided. Thus, contributions made by Dulbecco, Temin and Baltimore collectively established the functional role of RNA viruses in causing tumors in animals. Since 1970, our knowledge concerning the mechanisms by which these viruses cause tumors and transformation has exploded. 


\section{Box 2. RT Assay and the Discovery of HIV-1}

There was one serious gap that remained to permit the association of oncoviruses with the tumors in humans. Until that time, human oncoviruses were known to be only DNA viruses like the herpes viruses that cause cervical cancer or the Epstein-Barr virus that causes Burkitt's lymphomas. RNA viruses causing tumors in humans were yet to be discovered. The discovery of Reverse Transcriptase provided a powerful tool to recognize retroviruses and cleared the way for the discovery of HIV later. RT, being a RNA-dependent DNA polymerase, can generate cDNA using an RNA template, an oligo-nucleotide primer and deoxy-ribonucleotide building blocks. One of the deoxy-ribonucleotides could be radio-labeled so that the final product of the cDNA could be qualitatively detected on a polyacrylamide gel or using a filter-based assay. Cells infected with the virus are lysed and the cell extract is used as the source of RT in this assay. The appearance of a radio-labeled DNA fragment in the gel (from the RNA template used in the assay) would indicate RT activity in the cell extract, which in turn would be suggestive of the presence of a retrovirus, provided appropriate controls have been included in the assay. The RT assay thus served as a powerful tool to detect novel retroviruses with great efficiency. The RT assay, however, cannot determine specific identity of a retrovirus although the requirement for a specific divalent cation could permit additional characterization of the suspected retrovirus. Nevertheless, availability of RT revolutionized molecular biology since it became possible to make cDNA from any RNA. Thus, by the end of 1970s, two most powerful techniques, the RT assay and the cell culture, had been discovered and optimized. Only a few years later, these two techniques were to play a critical role in the discovery of HIV in the early 1980 s.

\section{Discovery of First Human Retroviruses HTLV-I and-II}

Since the time RT was discovered by Temin and Baltimore, several groups all over the world were actively engaged in hunting for viruses, especially retroviruses, that could be the cause of some cancers in human beings. One such group was that of Luc Montagnier at Pasteur Institute in Paris, France. By the time he started a virology laboratory at Pasteur Institute in 1972, Montagnier already was an expert on chicken oncogenic viruses. Like many scientists of his era, Montagnier too believed that RNA viruses, importantly retroviruses, could cause cancer in humans. Five years later, in 1977, Francoise Sinoussi too joined his group to aid him in the hunt for these viruses. Although their attempts did not succeed in identifying any such retroviruses, Montagnier's group developed a technique that enhanced isolation of retroviruses from mouse cells by blocking endogenous interferon. Interferons are cytokines (growth factors) made by the host cells to protect themselves from viral infection. Montagnier's 
group demonstrated that by blocking the interferons using specific antibodies, it was possible to make larger quantity of the virus from mouse cells infected with the virus.

Around this time, a different group at the National Institutes of Health (NIH), USA too was preoccupied with the hunt for human retroviruses. Unlike the French team, Robert C Gallo's group at the NIH met with significant and early successes in its quest. In 1978, Gallo's group reported the discovery of the first human retrovirus, Human T-cell Leukemia Virus Type 1 (HTLV-I). HTLV-I was the first of the only four retroviruses that infect human beings, the other three being HTLV-II, HIV-1 and HIV-2. HTLV-I is a retrovirus containing single-stranded RNA and causes cancers such as T-cell leukemia and T-cell lymphoma in adults. The American group succeeded in their attempts mainly because they improved the cell culture technique that permitted long-term culture of T-lymphocytes in the laboratory. Gallo and his collaborators discovered interleukine-2 (IL-2) which was the first cytokine to be identified. IL-2 is an important growth factor for the T-lymphocytes in the presence of which the cells proliferate at significantly higher levels. This was one of the most important technological developments that helped isolation of HIV eventually.

Although at the time of HTLV-I discovery by Gallo's group, an association between this virus and human cancers was not known, that link soon emerged. HTLV-I infection was endemic for several regions of the world including Japan. Depending on a few reports published by several Japanese groups on a puzzling outbreak of a form of viral leukemia in Japan, Gallo's group quickly guessed the involvement of HTLV-I and experimentally proved it. This finding was subsequently confirmed by several other groups from other parts of the world. In 1981, Gallo and his collaborators identified a second human retrovirus which was named as HTLV-II. Although HTLV-II was isolated from an individual suffering from a type of cancer called hairy cell leukemia, this virus was not particularly linked to any form of 


\section{Box 3. Human Retroviruses are CD4-tropic}

One of the distinguishing properties of these two viruses (HTLV-I and II) is their liking for the human CD4 positive T-cells. CD4 is a specific cellular receptor, a glycoprotein, expressed on the cell surface of a subset of T-lymphocytes. CD4 T-cells play a pivotal role in orchestrating a wide variety of immune responses including antibody secretion by B-lymphocytes, cell killing mediated by cytotoxic T-lymphocytes (CTL, these cells contain a different cell surface glycoprotein receptor called CD8), phagocytosis by macrophages and many other important functions. In the absence of CD4 cells or when their function is paralyzed in other contexts, the various functions of the immune system are significantly compromised (see Box 4). Importantly, other than these two retroviruses, no other parasite, bacterium, fungus, virus or any other pathogen demonstrates such specific liking (tropism) for CD4 cells (CD4 tropism). The CD4 tropism of the human retroviruses is the unique property that provided the most important clue later at the time of HIV discovery. HIV-1 and -2 also share the property, CD4 tropism, with HTLV-I and -II viruses.

human disease unlike its predecessor HTLV-I. Both HTLV-I and -II share several important biological properties including their CD4 cell-tropic nature (see Box 3).

The world medical stage was set for the performance of one of the leading viral actors, the human immunodeficiency virus. By 1981, Gallo's group not only identified two human retroviruses but also prepared the setting for the discovery of HIV-1 by developing an important cell culture technique. In 1982, Gallo received the prestigious Lasker Award: "For his pioneering studies that led to the discovery of the first human RNA tumor virus and its association with certain leukemias and lymphomas". Gallo was awarded his second Lasker Award in 1986 that he shared with Montagnier for "determining that the retrovirus now known as HIV-1 is the cause of Acquired Immune Deficiency Syndrome (AIDS)". Gallo is the only scientist to receive two Lasker Awards.

\section{Enter the HIV}

Starting from 1981, the early cases of a new human epidemic started emerging in USA in homosexual populations and hemophiliac patients. The world medical stage was set for the human immunodeficiency virus. 
In February 1982, at a research conference at Cold Spring Harbor in USA, Robert Gallo was the first one to suggest that AIDS was possibly caused by a retrovirus similar to HTLV.
In 1981, a research article appeared in a journal called Morbidity and Mortality Weekly Report which reported that members of a community of gay men in Los Angeles were dying of a fungal infection of the lung caused by Pneumocystis carinii. A few months later there appeared another small report in the same journal on a group of 26 young gay men in New York and California diagnosed with Kaposi's sarcoma, a rare form of skin cancer primarily seen in elderly men of Jewish and Mediterranean origin. These were the first reports on the beginning of an epidemic called 'the gay disease' at that time. What started as a trickle eventually turned out to be a tsunami during the following three decades and is today known as HIV/AIDS.

In February 1982, at a research conference at Cold Spring Harbor in USA, Robert Gallo was the first one to suggest that AIDS was possibly caused by a retrovirus similar to HTLV. Prior to that, James Curran of the Center for Disease Control in Atlanta, USA, proposed that AIDS was possibly caused by an infectious agent, most likely a new virus. Gallo's hypothesis that AIDS was caused by an HTLV-like virus was based on several observations. The most important clue came from data on blood transfusions in hemophiliacs. Hemophiliacs who received filtered clotting Factor VIII manifested symptoms similar to that of the 'gay disease'. Only a virus, not any other micro-organism, could have passed through the 0.45 micron filter used in filtering serum. Numerous clinical and laboratory observations suggested severe depletion of CD4 T-cells in AIDS suggesting that the infectious agent was CD4-tropic. Only the HTLV viruses were known to demonstrate such CD4 tropism until that time. The new virus therefore must be an HTLV-like virus. Some animal retroviruses, like the bovine leukemia virus (BLV), were known to cause immuno-suppression and AIDS in animals. The epidemiological data were also consistent with the idea of an infectious agent causing human AIDS. For instance, like in the case of HTLV-I infection, the risk of the AIDS virus infection too involved blood exposure, sexual contact and birth to an infected mother. While Gallo's laboratory initiated frantic search to test their hypothesis, they could not 
make immediate progress for technical reasons (see Section 6).

In the meanwhile, in France, in 1982, clinicians started noticing similar symptoms in their gay populations and hemophiliacs. Gallo's idea that a retrovirus could be the cause of AIDS was already known in France. A French clinician, Wily Rozenbaum Gallo's idea that a retrovirus could be the cause of AIDS was already known in France. working at the Hospital Bichat, was quite convinced that a new retrovirus was behind AIDS. Although his initial attempts at mobilizing virologists at the Pasteur Institute to join hands in studying the new disease were not successful, within a few months he could establish active collaborations with an important scientist at the Pasteur Institute, Luc Montagnier. Montagnier accepted to assist Rozenbaum in the study of the new disease and assigned this work to two other scientists in his laboratory, Francoise Barre-Sinousse and Jean-Claude Chermann. By this time, the French laboratory was equipped with the kind of expertise needed to identify new retroviruses. They knew how to work with animal retroviruses. Importantly, they had the knowledge of the new cell culture technology developed by Gallo's group in their attempt to isolate HTLV-I. As we discussed above, this technique involved supplementing the culture medium with the potent growth factor IL-2 that boosted the growth of the viruses more efficiently on host cells.

\section{The First AIDS Virus}

On 3rd January 1983, Rozenbaum sent the first clinical sample to Montagnier's laboratory. The sample was a lymph node biopsy taken from a person identified as BRU (the viral strain taken out from this person was also labeled as BRU later). The patient was a 33-year-old young homosexual with a lymphadenopathy in the neck. He had travelled to many countries during the previous years including North Africa, Greece, USA and India. He had had more than 50 sexual partners per year. His blood contained antibodies to cytomegalovirus and Epstein-Barr virus, both transmitted sexually. Herpes simplex virus could be isolated from his throat. He had had a history of several episodes of gonorrhea and was treated for syphilis in 1982. At the time of biopsy collection, 
The nature of the viruses isolated from the early phase of the infection is quite different compared to the ones taken out from the advanced stages. he did not have any active clinical symptoms like fever or weight loss. Of his T-lymphocytes, $44 \%$ were of CD4 helper type and $16 \%$ of CD 8 cytotoxic type.

Unfortunately, at that time, the technology was not yet developed to determine the absolute CD4 cell count by the technique known as 'flow cytometry', a practice mandatory today. CD4 count is usually suggestive of the clinical stage of the infection (see below). Even in the absence of this important information, the clinical profile of the patient is suggestive of early viral infection. The nature of the viruses isolated from the early phase of the infection is quite different compared to the ones taken out from the advanced stages. For instance, the viruses in the early stages do not proliferate rapidly when added to cells in the laboratory in contrast to the viruses isolated from the advanced stages that grow more aggressively and kill cells rapidly. The differences in the growth properties of the viruses have an important bearing on the subsequent viral contamination that originally happened in the French laboratory which led to a lot of confusion subsequently (see Sections 7 and 10). All that we must keep at the back of our minds at this time is that the virus isolated from the patient BRU in the French laboratory was the first ever HIV to be isolated and it was a slow- growing virus.

In the French laboratory, T-lymphocytes were isolated from the lymph node tissue and put into culture with a mitogen (any chemical that promotes cell division) called phytohemagglutinin that should activate the T-cells and as a consequence viral proliferation. The cell culture medium also contained IL-2 and antiinterferon antibodies that should further boost the viral growth. They isolated T-cells from the blood of the patient and started culturing them as described above. The idea was to see if it would be possible to detect proliferation of the virus in the laboratory. If the answer was yes, could the virus be isolated, as Gallo's group did previously for the isolation of HTLV-I? Following proliferation, the virus must be shed into the culture medium. They collected the culture medium at regular intervals and tested for the presence of Reverse Transcriptase with the help of the RT- 
assay described above. After 15 days, they could detect the presence of the RT enzyme activity only in the lymph node cells, but not in the blood cells, suggesting the proliferation of the virus. The enzyme activity continued for an additional 15 days and declined after that.

To confirm the presence of virus in the medium, they did several additional experiments including electron microscopy and immuno-precipitation of the viral antigens. The virus was grown in the presence of radio-labeled amino acids so that all the viral proteins were radio-labeled. The virus was then concentrated using ultracentrifugation, viral particles were lysed and specific antibodies were added to the viral soup. Antibodies specific to HTLV-I, HTLV-II were used in the assay. Additionally, patient BRU serum was also used in the experiment because it was likely to have antibodies to several viral antigens. If the antibodies are specific to viral antigens, they bind to the antigens and separate them from the rest. The viral antigens captured by the antibodies can be resolved by gel electrophoresis. Since these antigens were already radio-labeled, individual protein bands could be seen by exposing the gel to X-ray film. When they did the experiment, only the patient serum precipitated virus-specific antigens especially at $25 \mathrm{kd}$. HTLV-I, HTLV-II antisera or other control antisera failed to precipitate any protein band suggestive of the virus. This result suggested that the patient's lymph node cells certainly contained a virus that could be identified by his own antibodies to the virus. Additionally, this virus was not identical to either HTLV-I or HTLV-II. It must be a new virus. They stored all the samples appropriately for subsequent studies. They named the new virus Lymphadenopathy-associated virus (LAV) because it was isolated from a clinical stage characterized by lymphadenopathy typical of early phase viral infection. This name was eventually dropped and the AIDS virus was given a new name as we all know it as HIV today. A clarification on naming of the viruses is required here. LAV is the name given to the group of viruses and BRU is the name of the specific strain originating from a single subject.
The viruses in the early stages do not proliferate rapidly when added to cells in the laboratory in contrast to the viruses isolated from the advanced stages that grow more aggressively and kill cells rapidly. 
${ }^{1}$ Barre-Sinoussi $\mathrm{F}$ et al, Isolation of a T-Lymphotropic Retrovirus from a patient at Risk for Acquired Immune Deficiency Syndrome (AIDS), Science, Vol.220, pp.868-871, 1983.
${ }^{2}$ Robert C Gallo, The Early Years of HIVIAIDS, Science, Vol.298, pp.1728-1730, 2002.
The specific viral strain isolated from the patient BRU was designated as BRU, The French group published these results in May $1983^{1}$. This was technically the first scientific documentation of HIV.

Although the French group was the first to demonstrate the presence of a new virus in the clinical sample, their work suffered from several limitations. Their work consisted of only one patient, although a part of the work also involved a second patient. The cause and effect relationship between the viral presence and the disease was not established. In simpler terms, the presence of a specific virus in patient samples didn't mean that the virus itself was responsible for AIDS in that individual or in the world. The presence of the virus may have nothing to do with AIDS. The authors themselves admitted this weak link when they said in the publication that 'The role of the virus in the etiology remains to be determined'. The French group did not demonstrate that two or more successive batches of the virus harvested from the same or different rounds of infection were the same virus. To do this, one would require a large quantity of the virus. They could not grow the virus to large quantities for two important reasons, one, the viral strain BRU was a slow-growing virus and two, they did not have a T-cell line that can grow indefinitely in cell culture and support vigorous viral proliferation. This problem was eventually solved by Gallo's group when they developed stable T-cell lines for this purpose (see Section 6, pp.486-487). In summary, the French group was successful in isolating the first HIV from a subject but could not provide sufficient evidence that it was the virus that caused AIDS. In 2002 Gallo himself admitted that "the paper by Montagnier/Chermann group is unequivocally the first reported true isolation of HIV from a patient with lymphadenopathy. However, the cause of AIDS was still unknown".2

We will return to the BRU viral strain a little while later. Let us now turn our attention to the American group and see what they were doing in the meanwhile. 


\section{A Shower of Viruses}

It was in February 1982 that Gallo first suggested that an HTLVlike retrovirus might be behind AIDS. His group quickly set out to test this hypothesis way ahead of the French group which started its work only a year later in 1983. Although the American group had a head start, they hit a roadblock as quickly as they made the beginning. Within eight months, by February 1983, the American group grew viral strains from at least five different AIDS patients while the French group was still organizing itself. Unfortunately for the Americans, they did not realize that all these viral strains belonged to the same AIDS virus mainly because of one serious technical problem. They did not have sufficient quantities of any of these viruses to compare them with one another in a range of biochemical, immunological and molecular analyses. They failed to grow sufficient quantities of the viruses because the cells on which the viruses propagated died very rapidly. Gallo's group subsequently generated a series of T-cell lines that solved the problem of virus production ${ }^{3}$. From electron micrographs of the viruses, they knew that these viral strains did not belong to HTLV-I or -II nevertheless were related to the HTLV family. The organisms were retroviruses because they made Reverse Transcriptase. What the American team did not realize at that time was that all these viral strains were the same. They also thought their viruses were not related to the French virus BRU because of the following reason: the French virus was docile, did not grow rapidly and kill the cells vigorously. In contrast, all the American viruses were cytopathic - they grew rapidly and killed the cells very quickly. Because of these important differences in the behavior of their viruses, the American team believed that their viruses, but not the French virus, were the real AIDS viruses.

At that time, neither the French group nor the American team was aware of a very important biological property of the AIDS viruses. The AIDS viruses differ significantly in their cytopathic and other biological properties depending on from which clinical stage the viral isolates are obtained (see Box 4).
3 Popovic $\mathrm{M}$ et al, Detection, Isolation, and Continuous Production of Cytopathic Retro-viruses (HTLV-III) from Patients with AIDS and Pre-AIDS, Science, Vol.224, pp.497-500, 1984 


\section{Box 4. Biological Properties of AIDS Viruses}

In the absence of medical intervention, the viral infection of human beings could be divided into at least three distinct phases (Figure 3), depending on the viral load (number of viral particles per ml of blood), CD4 cell count (number of CD4 T-cells per micro-liter of blood) and clinical symptoms. In the first phase, the acute viremia, viruses grow to very large numbers as the immune components, like the cell-mediated immune response and antibodies that can control the virus, are not yet activated. The CD4 cells, approximately 1,000 cells per micro liter of blood, show a quick dip but recover soon. The infected person shows several general signs of an infection: fatigue, fever, etc., but these symptoms are short-lived and not suggestive of an infection by the AIDS virus specifically. The entire phase lasts approximately 3 to 6 months. The second phase begins with the activation of the immune responses that control the viral proliferation efficiently, nevertheless cannot eliminate the virus. Immune activation results in a great dip in the viral load until it reaches a specific low level technically called the viral 'set-point'. The viral set point is variable in different people. In some it is leveled off at a higher level and in others at a much lower level but, by and large, it remains stable over a few years, typically 5 to 10 years. Throughout this phase the infected person remains healthy and shows no signs of weakness or disease. Nevertheless, inside, the CD4 cells keep falling at a slower but steady rate. In other words, although not visible, the virus continues to destroy the $\mathrm{CD} 4$ cells and the immune architecture at a slow and steady rate. This second phase that lasts over a few years is called 'the clinical latency' because there are no apparent signs of the viral infection. When the CD4 count drops below a certain limit, believed to be 200 to 350 cells per micro-liter, after a few years, the immune system starts showing signs of deterioration or 'immunodeficiency'. Opportunistic microorganisms like cryptococcus, Candida, Mycobacterium tuberculosis and many others, exploit the situation. The AIDS

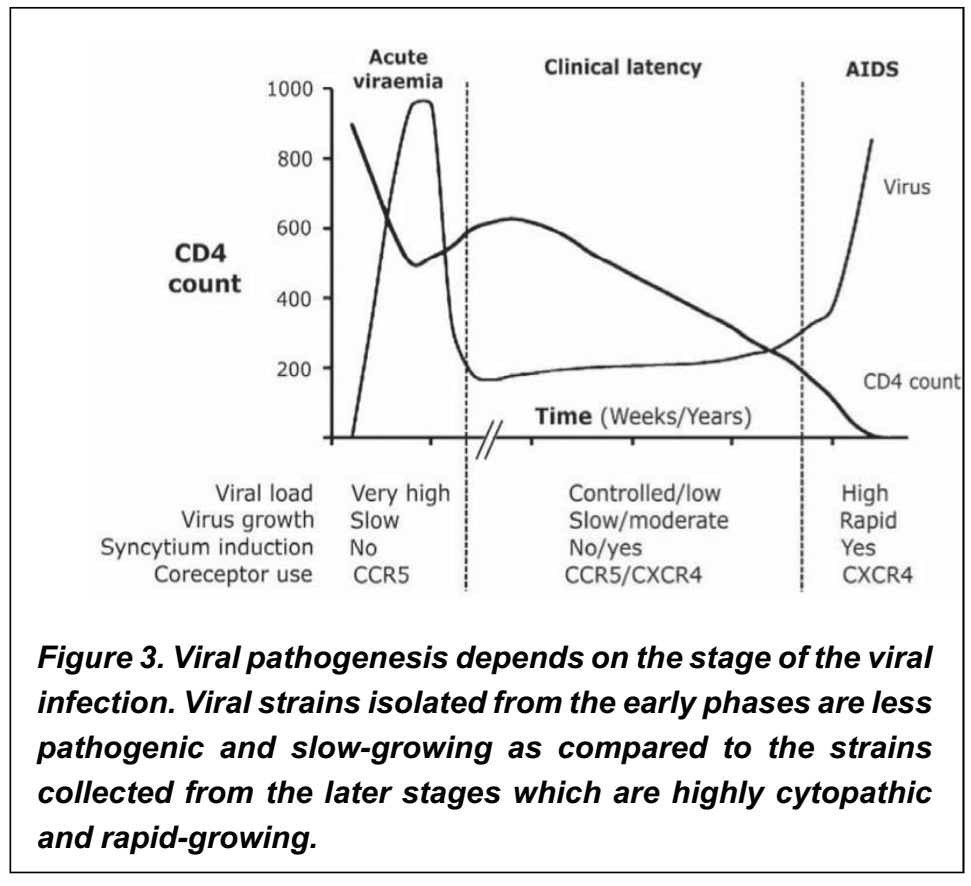
virus starts growing again in large numbers. This last phase of the infection, characterized by opportunistic infections, tumors, CD4 cell dip and viral reemergence, is called AIDS. From the onset of AIDS, an infected person dies in a few months or years.

Box 4. Continued... 
What is intriguing and yet not completely understood is that the virus also seems to change some important biological properties from the time of the early infection to the time of AIDS. We all know that the AIDS virus needs a cellular receptor called CD4 on the target cell for infection. In addition to CD4, the virus also needs a second receptor on the target cell for infection and entry, which is called a 'coreceptor'. There are two major coreceptors that the virus uses for cell entry, CCR5 and CXCR4. For reasons still not understood completely, the early virus which starts an infection in a new individual invariably uses only CCR5 but not CXCR4. Although the body has several target T-cells that express CXCR4, paradoxically, the virus will not use this coreceptor in the early phases of the infection. Surprisingly, again for reasons not yet understood, as the infection matures and progresses into AIDS, the virus switches its preference for the coreceptor from CCR5 to CXCR4. Viruses isolated from the AIDS phase predominantly use CXCR4. They do not use CCR5 anymore. Depending on the coreceptor preference, the viral strains are classified into R5 or $\mathrm{X} 4$ viruses. $\mathrm{R} 5$ viruses are seen in the early phases of the infection and $\mathrm{X} 4$ viruses in the late phase. The switch in the preference for the coreceptor happens gradually over a long period of time. We therefore can also see viruses that use both the coreceptors (R5/X4 viruses or dual-tropic strains) during the intermediary stages of the infection. We are examining the coreceptor requirement of the AIDS virus in greater detail to understand why the scientists in the beginning failed to realize that the French virus and the American viruses were the same AIDS virus.

The R5 virus is not only the early virus but it also grows at a very slow rate in the laboratory. Furthermore, the R5 virus is also less cytopathic as it doesn't kill the cells at a rapid rate. Importantly, R5 virus can infect primary T-cells isolated from the blood but not the T-cell lines. This is because the standard T-cell lines like Jurkat, H9 and others express CD4 and CXCR4 but not CCR5 (Figure 4). Primary blood cells in contrast express all the three surface receptors, CD4, CXCR4 and CCR5. Since T-cell lines do not express CCR5, viruses isolated from the early
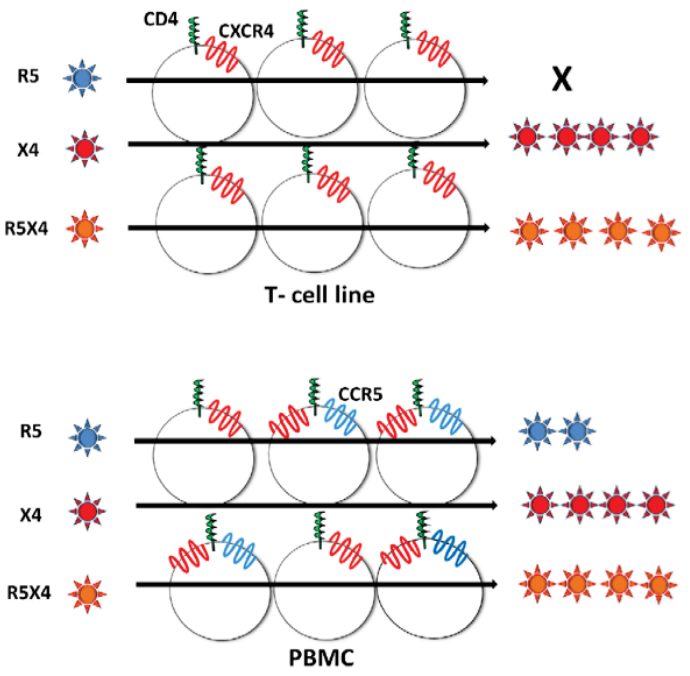

Figure 4. Most of the T-cell lines used in the laboratory express both CD4 and CXCR4, but not CCR5 (top panel). Primary blood cells (PBMC), in contrast, collectively express all the three receptors CD4, CCR5 and CXCR4 (bottom panel). X4 viruses can grow on the standard $T$ cell lines as well as PBMC with equal efficiency. $R 5$ viruses can grow only in the PBMC but not on the T-cell lines because these cells do not express CCR5. Dual-tropic viruses can grow either in T-cell lines or PBMC like X4 viruses.

Box 4. Continued.. 
phases, R5 strains, cannot grow on them. In contrast, viruses isolated from the later phases, X4 viruses, can grow on any T-cell line and also on the primary cells. Importantly, X4 viruses also differ from the more sluggish R5 virus in their growth dynamics. $\mathrm{X} 4$ viruses are quite aggressive, grow quite rapidly on any cells and in the process kill the cells quickly. X4 viruses also induce membrane-to-membrane fusion of T-cells as a result of which several cells fuse into one single huge cell mass but the nuclei remain independent (Figure 5). This cell fusion leads

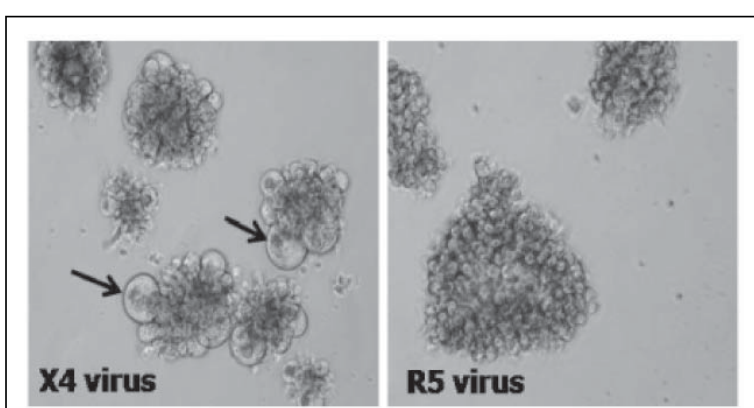

Figure 5. Only X4 viruses (NL4-3 strain, left panel), but not $R 5$ viruses (Indie, a subtype-C strain, right panel), can induce syncytium formation.

to the formation of a large size multi-nucleated cell mass that is an outcome of tens and hundreds of cells fusing together. This multi-nuclear cell mass called 'syncytium' has a typical globular and transparent appearance. Gallo's group initially used the syncytium-inducing property of the AIDS virus to detect infection in the cells. Unlike the X4 viruses, the R5 strains do not usually produce syncytia in target cells. The coreceptor requirement of the AIDS viruses was understood only after 1995 following an important publication by Gallo's group ${ }^{4}$ but not way back in 1983 ..

${ }^{4}$ Cocchi F et al, Science,Vol. 270, pp.1811-1815, 1995.

The French virus BRU was isolated in the early phases of the infection therefore it was an R5 virus and did not grow aggressively and kill cells rapidly. In contrast, the American viruses were isolated from patients in the advanced stages of the disease. They were all therefore X4 viruses. They grew aggressively, killed the cells rapidly and unlike the French virus, were more cytopathic. Because of these biological differences, the American group erroneously assumed that their viruses were different from the French virus. Furthermore, since they did not realize that they were all different strains of the same AIDS virus and felt that the data were not sufficiently convincing of their real identity, they did not publish their results in 1983. However, several people doubt if Gallo's laboratory really had all these viruses at this time.

The major breakthrough came for the American team in November 1983 when they developed a series of T-cell lines from an 
original T4 leukemia parental cell line. These new T-cell lines produced very large quantities of virus rapidly without themselves dying. Using the new T-cell lines, the American group produced large quantities of the viruses readily available in their laboratory and also grew many more new viruses. The cell lines were given out to many other laboratories (although there was a dispute regarding this claim) where they served a similar purpose. One of the daughter T-cell lines, H9, established at that time is quite popular even today. It is important to remember that R5 viral strains cannot grow on these T-cell lines because these cells do not express CCR5 (Figure 4).

Over the next four to five month period, the American group isolated several viruses, grew them in larger quantities and analyzed them using a range of experimental strategies including molecular, biochemical and immunological approaches. Considering the biological and epidemiological similarities with HTLVI and -II, they gave a collective name to all the new viruses as HTLV-III. As suggested by the electron microscopy and immunology assays their viruses, however, were different from HTLVI and -II. It was much later that this classification of the AIDS virus by Gallo's group was found erroneous and the new viruses were placed in a different branch of human retroviruses now solely occupied by HIV-1 and -2 (see Box 5). Both HTLV-I and HTLV-II were simple retroviruses and not as pathogenic as HIV1 and HIV-2. Additionally, while HTLV viruses are associated with human tumors, the HIVs do not directly cause cancer in human beings. At the genetic level, the HIVs are more complex

\section{Box 5. HIV Nomenclature}

The AIDS virus was originally named as LAV (lymphadenopathy-associated virus) by the Montagnier's group and as HTLV-III by the Gallo's group. In 1986, an international committee consisting of several reputed virologists, including Montagnier but not Gallo, named the AIDS viruses as human immunodeficiency virus (Coffin J et al, Science, 232, 697, 1986). While Gallo resisted the use of any name for the AIDS virus other than HTLV-III, Montagnier cooperated with the international committee to designate the virus with a name technically more appropriate (http://profiles.nlm.nih.gov/MV/Views/Exhibit/narrative/aids.html). 
and have different regulatory genes (tat and rev) and additional accessory genes (nef, vpr, vpu,vif) that are not present in HTLVs. In May 1984, the American group reported their findings in a series of four publications in a single issue (Vol. 224) of the journal Science.

So far we have seen how HIV was discovered and how the field progressed towards the discovery of the AIDS virus. Now we are going to turn our attention to the second and bitter part of the article. The controversy surrounding the Nobel Prize award for the discovery of HIV must be looked into. Why was Gallo's name not considered for the award despite his significant and important contributions? What was the origin of the dispute between the American and French laboratories that dragged their respective governments into locking horns? These are the questions that we must consider now. To seek answers for some of these questions, we must travel back to 1983 when the trouble began. The battle revolved around two important issues between the French and the American groups, first, on the question of who should get credit for the discovery of HIV and second, who should have rights on the patent for a blood test for HIV diagnosis. A third component, an inadvertent contamination of the viral samples in the French laboratory further complicated the matters.

Contamination occurs when proper operational practices are not in place or not implemented strictly, when the researchers involved are less experienced or when they don't take appropriate care.

\section{Viral Contamination}

We must familiarize ourselves with three different viral strains of HIV because these are the three viruses that are going to play an important role in this story. We have familiarized ourselves already with the first virus BRU which was isolated in the French laboratory. The second virus LAI was isolated by the French group a few months later from a young homosexual person. The third virus IIIB was isolated in Robert Gallo's laboratory a few more months later.

Contamination is a serious problem in research laboratories. It could happen between any two reagents that are similar in their physical properties like two vectors, proteins, cell lines, bacteria, 
viruses. Contamination occurs when proper operational practices are not in place or not implemented strictly, when the researchers involved are less experienced or when they don't take appropriate care. Despite all precautions, contamination can still happen. When a contamination takes place, the identity of the sample or reagent will be misunderstood until the problem is discovered much later.

After the successful isolation of the BRU viral strain and naming the family of the viruses as LAV, in 1983, Montagnier's group set out on isolating more viruses from other patients. A few months later they received blood and lymph node samples from a young gay man identified as LAI who was suffering from Kaposi's sarcoma. A virus could be isolated from his blood without much difficulty and this viral strain was named LAI. Around the same time, they isolated a third virus from the blood of a Zairian woman which was named Eli. This woman was suffering from full blown AIDS and died within a week. Unlike the first virus BRU, these two viruses isolated from the AIDS stage, LAI and Eli, were very aggressive and quickly killed the cells on which they were growing. Furthermore, unlike BRU, these viruses grew on T-cell lines efficiently. For these differences, Montagnier thought that the viruses belonged to a different group as compared to BRU, and called them with a generic name, immune deficiency-associated viruses (IDAV). Because of its aggressive nature of proliferation, LAI contaminated some of the BRU viral cultures in the French laboratory sometime around October 1983. They did not know this.

In line with the practice common in the research community, the French group shared their viruses with several laboratories worldwide. Starting from July 1983 over several months, they shipped multiple samples of BRU to many laboratories including to Gallo's laboratory. The samples were sent with an understanding and condition that they would not be used for a commercial application. Neither the laboratory sending the samples nor the laboratories receiving them knew that some of these batches labeled as BRU were contaminated with the more aggressive 
When two different viruses are put together into the same culture, over a period of time, the more aggressive virus will dominate the submissive one to the extent that one of the viruses can even vanish completely.
${ }^{5}$ Robert C Gallo, The Early Years of HIVIAIDS, Science, Vol.298, pp.1728-1730, 2002. virus LAI until much later. When two different viruses are put together into the same culture, over a period of time, the more aggressive virus will dominate the submissive one to the extent that one of the viruses can even vanish completely. LAI virus in the disguise of BRU reached many laboratories and their cultures too. Some of these samples labeled as BRU were completely LAI and some others were a mixture of BRU and LAI, as was discovered later. We shall return to the LAI virus a little while later. Let us see now how the saga for fame unrolled.

\section{Beginning of the Trouble}

When Gallo visited Montagnier's laboratory in 1984, it was clear to both the scientists that each had viruses that they independently believed to be the right kind of viruses causing AIDS. They not only believed that their own virus was the right one but also that the other virus was a wrong one. Regardless of this discordance, the two groups agreed to publish their work together, though as independent publications, exchange reagents and organize a joint press conference. Remember Montagnier had already published their Science paper in May 1983 describing the BRU virus isolation which the French team called LAV. Gallo's group was yet to come out with the series of the 1984 Science publications describing their viruses which they collectively called HTLVIII. One specific viral strain, called IIIB, among these viral strains stood out for its aggressive growth properties. This virus could grow rapidly to very high numbers on any cell line. Gallo's group selected IIIb for the diagnostic assay they planned to develop because of the ease with which this virus could be cultured in the laboratory. At the time of the meeting, neither of the scientists knew that both the French virus BRU and the American virus IIIB belonged to the same AIDS virus family. Gallo's laboratory was actively involved in characterizing the IIIB virus. Gallo agreed to the proposal that a joint press meeting was to be organized, involving both of the French and American groups, if the IIIB virus turned out to be the same as BRU belonging to the AIDS virus family ${ }^{5}$. 
When Gallo arrived back home from France, the scenario, however, changed. In a hurriedly convened press meeting on 23rd April 1984, Margaret Heckler, secretary of the Department of Health and Human Services (DHHS), announced that Gallo had discovered the virus that caused AIDS, that it was named HTLVIII and that there would be a commercially available blood test for AIDS soon. Gallo too stood in front of the press gathering and gave a seminar describing the discovery of the AIDS virus by his group and showing them pictures of the virus taken using the electron microscope. In the entire press conference, he did not make any mention of Montagnier. Additionally, there was even controversy and evidence that the photos of the virus used by Gallo in the press meet actually belonged to the French data. Investigation committees later identified that the virus photos shown at the conference were actually taken from the French team without their knowledge. Importantly, Gallo was fully aware of the contributions made by the French group at the time of this press conference. In fact, the French group had already published their finding a year ago whereas Gallo's publications were yet to be reported a week later.

The French group obviously did not like this. Gallo later blamed it on the circumstances, a leak to a freelance journalist on the discovery of the AIDS virus that forced his Institute to convene the urgent press conference. He regretted that the French scientists were left out from the meet. However, he ignored two critical questions. What prevented him from mentioning the role played by the French scientists in the discovery of the AIDS virus at the press meet? And, when a published document was already available on the discovery of the AIDS virus, how could the American group make a claim for the same, that too a year later? A third question must be added here. How could he make a claim that the cause and effect relationship between AIDS and the viruses was established? His Science publications, yet to appear, did not satisfy the $\mathrm{Koch}^{6}$ postulates to justify such a claim (see Box 6). There were no answers to any of these questions. Like the LAI

${ }^{6}$ Robert Koch, Resonance, Vol.11, No.9, 2006. virus did to other viruses, Gallo and the US government simply 


A blood test like
ELISA could detect
infected individuals
in the prolonged
latency period and
prevent viral
transmission
significantly and
contribute
positively for the
viral control.

attempted to bulldoze Montagnier and the French government out of the competition. They, however, were not quite successful in doing this.

\section{A Mockery of Patents and Politics}

Soon after isolating the first AIDS virus BRU, the French group set out to develop a blood test to detect infected individuals. The test was based on the principle of ELISA that detects virusspecific antibodies present in the blood or other body fluids. This test was important because of the unique nature of the viral infection. There is a prolonged phase of the viral infection called the clinical latency (Figure 3) that typically lasts 5-10 years, during which period no clinical symptoms are manifested. A blood test like ELISA could detect infected individuals in the prolonged latency period and prevent viral transmission significantly and contribute positively for the viral control.

Montagnier and his coworkers applied for a patent of the United Kingdom on 15th September 1983 and for a US patent on 5th December 1983. This application was kept pending at the US patent office for years before finally rejecting it. In the meanwhile, soon after the press conference on 23rd April 1984 where a unilateral and unfair claim was made by the American team for the discovery of the AIDS virus, on the same day, Gallo and Popovic applied for a US patent for a diagnostic kit for AIDS. A year later on 28th May 1984, the US Patent and Trademark Office awarded an American patent to Gallo and DHHS for the AIDS diagnosis. The French application which was filed 17 months earlier was still kept pending in clear violation of the patent norms. A lot of money was at stake. The patent would be worth about $\$ 100$ million (500 crores) a year. Several companies already applied for licenses to develop a commercial kit from this technology. The American government agencies clearly did not want the French to take precedence over an important matter like this.

Gallo's patent application was the beginning of the long-drawn 
dispute, legal battles and high-level diplomatic negotiations between the USA and France. The dispute on who discovered the AIDS virus became the matter of legal tussle between the Pasteur Institute in France and the Department of Health and Human Services in the USA, each side claiming the patent rights. The Pasteur Institute, assignee of the Montagnier's patent application, challenged the US patent in court. In his defense, Gallo did not deny that Montagnier identified the virus first, but he argued that it was he who established the relationship between AIDS and the virus and that this proof was obtained using an independent virus, IIIB, isolated in his own laboratory. The first level of dispute between the two scientists ended with an out of the court settlement, to the surprise of many in the scientific community, mediated by Jonas Salk, the famous scientist and Nobel Laureate who made the polio vaccine. The sparring between the two scientists, nevertheless continued until a very high profile meeting took place in 1987 between the Prime Minister of France, Jacques Chirac and The President of USA, Ronald Reagan. In this meeting they announced that the credit for identifying the virus will be shared by both the scientists. Additionally, both the warring camps agreed for an equal share over the patent royalties. There was peace at last.

Peace, however, was bought in a miscalculated understanding that the Gallo's virus IIIB was different from the French virus LAI. The scientific community was soon to learn that these two individual viral strains in fact were one and the same virus, the French virus!

\section{Back to the Viral Contamination}

By the end of 1985, several AIDS viruses, including the French viruses BRU and LAI and the American virus IIIB, were molecularly cloned and the full-length nucleotide sequences were determined. When the sequences were compared to understand to what extent all these viruses were related to each other, researchers were in for a shock. The American virus IIIb was nearly identical to the French virus LAI (Figure 6). Even by 1985, the enormous
The first level of dispute between the two scientists ended with an out of the court settlement, to the surprise of many in the scientific community, mediated by Jonas Salk, the famous scientist and Nobel Laureate who made the polio vaccine. 
Figure 6. Phylogetically LAI and IIIb strains are closely related. Phylogenetic analysis compares sequences and determines how close or distant two different related organisms are. Several HIV-1 subtype$B$ viral strains and one subtype-C strain have been compared here. As expected, the subtype-C strain is located farthest from all the other viral strains. The French LAI strain and the American IIIb are the nearest to each other on the same branch suggesting that they are not two but the same viral strain. The scale below indicates the genetic distance between the viral strains.

${ }^{7}$ S Wain-Hobson et al, Science, pp.252,pp.961-965, 1991.

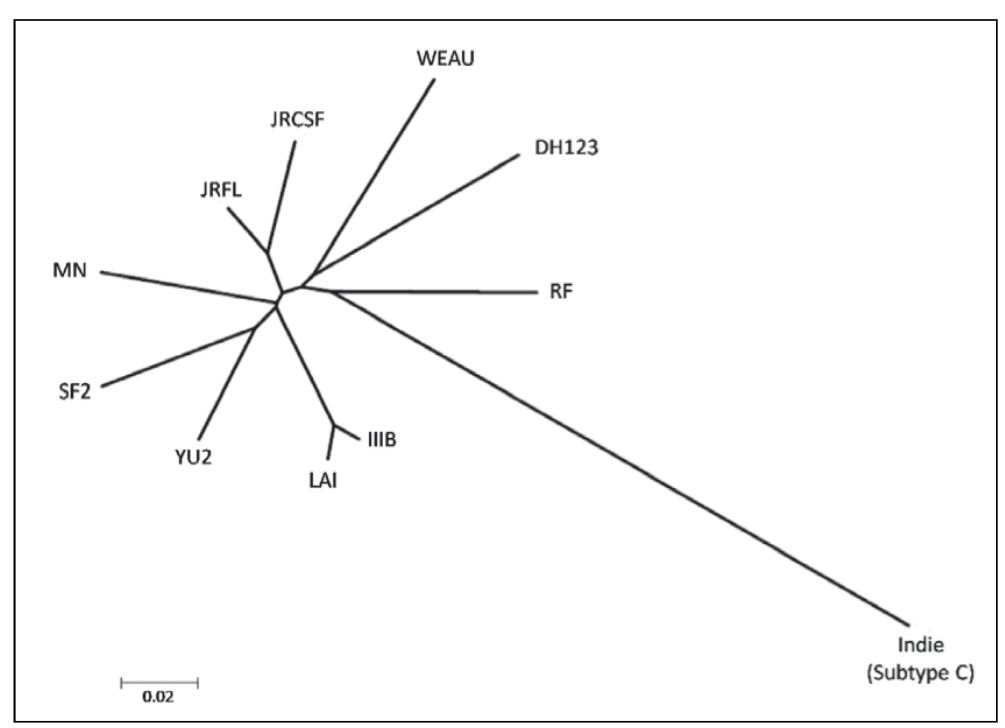

magnitude of genetic diversity of the AIDS virus was very well appreciated. Most of the AIDS viruses from different patients differ by at least 6-20 percent because of the remarkable ability of the virus to mutate. However, the American virus IIIB was less than 2 percent different from the French virus LAI, leading to the suspicion that both viruses were from the same source. Individual viral strains isolated from even a single individual could have significant level of genetic diversity. In this backdrop, it was unimaginable that two different viruses, isolated continents apart so closely resembled each other. One possibility was that the two individuals from who the viruses isolated were sexually related to each other. A more probable explanation is the inevitable contamination that happens in the laboratories. A few years later, in a series of experiments, the Montagnier's group traced the contamination to a few batches of viral cultures ${ }^{7}$. Removing several stored viral preparations from their freezers and subjecting them to rigorous experimental analyses, they traced the contamination to a few individual viral preparations that were sent out to many laboratories including Gallo's laboratory, unaware that they were contaminated.

After reporting the first AIDS virus BRU in May 1983, the Montagnier's group set out on isolating viruses from several 
other patients. By May 1984, they isolated 12 additional viruses from other patients. One of these viruses was LAI derived from a homosexual man with Kaposi's sarcoma. LAI was one of the most aggressive viruses which contaminated several batches of other viruses in the French laboratory. LAI also travelled to Gallo laboratory under the disguise of BRU from Montagnier's laboratory in more than one batch. It is possible that LAI contaminated some of the American cultures that were designated as IIIB. Alternatively, it is possible that the American scientists realized the merits of LAI, misappropriated and renamed it as IIIB. It is practically impossible now to distinguish between these two possibilities to unearth the truth. It is more so given the allegations that the notebooks in Gallo's laboratory containing records of experimental details were tampered with, missing or not available for an investigation.

\section{For a few Dollars More}

The situation became aggravated with the disclosure that IIIB was nothing but an alternative form of the French virus LAI. Realizing that the blood test patented by Gallo solely depended on a French virus, not an American one, the Pasteur Institute demanded that the USA should drop its patent claims completely and turn over the patent royalties to the French in entirety. In July 1994, the Department of Health and Human Services of the USA acknowledged that the virus used by Gallo to develop the diagnostic test indeed was based on the French virus. However, they agreed to provide the French with a few more millions of dollars in patent royalties without dropping the US claims completely.

Gallo's situation became critical after John Crewdson, a reporter, published an investigative report in Chicago Tribune questioning whether Gallo's laboratory stole the virus from the French. This was the beginning of Gallo's woes. Starting from this time he had to face several investigative committees until he was finally absolved many years later. To review the investigations conducted by numerous committees and their deliberations is beyond the scope of this article. However, it stands out that most of these
Realizing that the blood test patented by Gallo solely depended on a French virus, not an American one, the Pasteur Institute demanded that the USA should drop its patent claims completely and turn over the patent royalties to the French in entirety. 
committees worked with a single objective: to protect Gallo and the US interests. If smaller committees found him guilty of scientific fraud, much higher committees would absolve him and give him a clean chit for lack of convincing evidence. For instance, a committee constituted in 1989 by the Office of Scientific Integrity after examining the record books from Gallo's laboratory and interviewing scores of people involved in the work, concluded that both Gallo and his associate Mikulas Popovic, were guilty of misconduct. After receiving the report, Bernadine Healy, the then director of the National Institutes of Health and Gallo's superior ruled that the evidence showed against Popovic was substantial making him guilty of misconduct but Gallo was not guilty. With this ruling, the charges against Gallo were reduced from theft of the French virus to less serious accusations that he attempted to garner more credit than what he deserved and that he made false statements or avoided giving proper credit to the French group. The director ordered replacing an investigator, Suzanne Hadley, because the latter refused to rewrite the report softening the criticism on Gallo. Finally, on 13th November 1993, four year since the investigations began, the Office of Scientific Integrity absolved Gallo because the department "now applies different standards ...".

\section{The Nobel Prize}

A Nobel Prize for the discovery of HIV has been expected for a long time. The question of Montagnier getting the Nobel Prize was never in doubt. Whether Gallo would make it was unclear. The dispute of whether or not Gallo should receive the Nobel Prize had been a long-drawn battle fiercely fought at many a forum over the years. For instance, in a recent letter that appeared

8 Kein G et al, Unsung Hero Robert C Gallo, Science, Vol. 323, pp.206-207, 2009. in Science, 105 scientists complained bitterly that Gallo was left out from the Nobel Prize ${ }^{8}$.

Both Montagnier and Gallo made significant contributions towards our understanding of the AIDS viral infection and the disease. Gallo's contributions, in this regard, have been much more important. Both these scientists have received several hon- 


\section{Box 6. Koch's Postulates}

Nearly 90 years ago in 1890, prior to the discovery of HIV in 1980s, Robert Koch and Friedrich Loeffler developed criteria to establish a causal relationship between a causative microorganism and a disease. These criteria, popularly known as the Koch postulates, were used by Koch himself to establish the etiology of tuberculosis and anthrax. These postulates underwent significant improvements initially by Koch himself and subsequently by others to accommodate them to fit a broader context. According to Koch postulates, (1) a microorganism must be found in the body of the host suffering from the disease (2) the microorganism must be isolated from the host and grown in pure culture (3) the cultured microorganism should cause disease when introduced into a healthy host and (4) the microorganism must be reisolated from the experimental host and identified as being identical to the original microorganism. From the above it is clear that both of the French and American groups successfully accomplished the objectives 1 and 2, but not 3 and 4 of the Koch's postulates. It is for this reason neither Montagnier nor Gallo could be given the credit of establishing the causative relationship between HIV and AIDS.

ors for their achievements. Nevertheless, looking at various works of literature carefully, one would realize that a myth has been built around Gallo over the years. The myth is the following. 'The general understanding' today is that while Montagnier was the first to isolate the AIDS virus, it was Gallo who 'accomplished' to establish the cause and effect relationship between the virus and AIDS. This statement and many others that reinforce this notion are far from the truth. The single publication of Montagnier in 1983 and all the publications of Gallo in 1984 collectively did NOT establish that AIDS was caused by their viruses. All these publications only demonstrated a significant correlation, but not an association, between AIDS and the isolated viruses. In fact, neither of these groups even knew that they were fumbling with the same virus. Neither the French team nor the American group through their early publications fulfilled the Koch's postulations to prove beyond doubt that HIV caused AIDS (see Box 6). This objective has been fulfilled in the subsequent years by the contributions of numerous laboratories spread all over the world (see Box 7).

The Nobel Prize is the most prestigious award given for "honoring the first discovery' in biomedical sciences. After the rightful decision by the Nobel Committee to honor Luc Montagnier and

\section{Suggested Reading}

[1] Luc Montagnier, A History of HIV Discovery, Science, Vol.298, pp.17278, 2002.

[2] Robert C Gallo, The Early Years of HIV/AIDS, Science, Vol.298, pp.1728-30, 2002.

[3] HIV, HPV Researchers Honored, But One Scientist is Left Out, Science, Vol.322, pp.174-5, 2008.

[4] Lisa Rainey, Who discovered HIV: Gallo, Montagnier or both? Jul 6, 2006. http://www.dallasvoice. com/artman/publish/ printer_2666.php 


\section{Box 7. Proof that HIV causes AIDS}

For ethical reasons, objective 3 of the Koch's postulates cannot be accomplished in human beings. One cannot purposefully infect a healthy person with HIV to examine development of AIDS in that person eventually. Furthermore, experiments involving HIV inoculation into experimental animals like chimpanzees or infection of primates with HIV-like viruses cannot be considered a substitute to satisfy this requirement. This requirement, however, has been fulfilled by the unfortunate incidences of accidental injuries and natural infection of human beings by HIV. Several health care workers have been accidentally injured by contaminated needles. Some of them eventually developed AIDS and their immune system was found to be immunodeficient. Viruses isolated from such people were shown to be identical to the parental viral strains. Similar accidental inoculations also happened during blood transfusion especially in the early days when blood screening procedures were not yet implemented. Many of such blood recipients became infected, developed antibodies to the virus, their immune system gradually underwent immunodeficiency and they developed AIDS. HIVinfected mothers have been known to give birth to twins where one twin is HIV-positive and develops AIDS, while the other child shows no sign of HIV and remains clinically and immunologically normal. Viruses isolated from sexual partners could also be shown to be genetically identical. From numerous and meticulous experiments from several clinics and laboratories world-wide, the causal relationship between HIV and AIDS has been eventually established.

Acknowledgements: The author would like to thank Drs. Nadula Raghu Ram and Karna Venkata Ramana for critical reading of the manuscript.

\footnotetext{
Address for Correspondence Udaykumar Ranga Molecular Biology and Genetics Unit Jawaharlal Nehru Centre for Advanced Scientific Research Bangalore 560 064, India. Email: udaykumar@jncasr.ac.in
}

Francoise Barre-Sinoussi, the disputes, debates and speculations over the Nobel Prize have drawn to a close. Following the first report on the viral isolation by the French group in 1983, a large number of laboratories, including Gallo's laboratory, made several important contributions to HIV/AIDS enriching our knowledge and drawing us closer and closer to efficient disease management.

Indeed Gallo's contributions to HIV/AIDS have been significant. However, he was not the first one to report isolation of HIV. His deliberate attempt at not giving due credit to Montagnier's work at the press conference in 1984 was not only irresponsible but should be considered as scientific misconduct. The viral strain mix up, perhaps is an unfortunate and inevitable accident and a benefit of doubt could be given to him. However, he demonstrated a potential for stealing credit from others to boost his own image and position.

From great scientists like Robert C Gallo, we must learn how not ought to be. 